\title{
Phylogeny and evolution of Burmanniaceae (DiOSCOREALES) BASED ON NUCLEAR AND MITOCHONDRIAL DATA ${ }^{1}$
}

\author{
Vincent Merckx, ${ }^{2,5}$ Peter Schols, ${ }^{2}$ Hiltje Maas-van de Kamer, ${ }^{3}$ Paul Maas, ${ }^{3}$ Suzy Huysmans, ${ }^{2}$ \\ AND ERIK SMETS 2,4
}

\begin{abstract}
${ }^{2}$ Laboratory of Plant Systematics, K.U. Leuven, Kasteelpark Arenberg 31, BE-3001 Leuven, Belgium; ${ }^{3}$ National Herbarium of the Netherlands, Utrecht University Branch, Heidelberglaan 2, NL-3584 CS Utrecht, the Netherlands; and ${ }^{4}$ National Herbarium of the Netherlands, Leiden University Branch, P.O. Box 9514, NL-2300 RA Leiden, the Netherlands
\end{abstract}

\begin{abstract}
The mycoheterotrophic Burmanniaceae are one of the three families currently recognized in the order Dioscoreales. Phylogenetic inference using nucleotide sequences of the nuclear $18 \mathrm{~S}$ rDNA region and the mitochondrial nadl $b$-c intron revealed two well-supported, major lineages within the family, corresponding to the two tribes recognized in the family: Burmannieae and Thismieae. All data supported a strong relationship between Thismieae and Tacca (Dioscoreaceae) making both Burmanniaceae and Dioscoreaceae polyphyletic. The three largest Burmanniaceae genera, Burmannia, Gymnosiphon, and Thismia, are paraphyletic. The splitting of Burmanniaceae into Burmannieae and Thismieae indicates two independent origins of mycoheterotrophy and correlated loss of chlorophyll in Dioscoreales. In the genus Burmannia, in which many species still contain chlorophyll, the achlorophyllous species are nested in between the autotrophic species, suggesting many independent changes from autotrophy to heterotrophy or vice versa. A Bayesian relative rates test on the $18 \mathrm{~S}$ rDNA data showed considerable variation in substitution rates among Burmanniaceae. The substitution rates in all Thismieae and many Burmannieae are significantly faster than in Dioscoreaceae, but there seems to be no correlation between rate increases and the loss of photosynthesis.
\end{abstract}

Key words: 18S rDNA; Burmanniaceae; Dioscoreales; molecular phylogeny; mycoheterotrophy; nadl $b$-c intron; Thismiaceae.

Nonphotosynthetic mycoheterotrophic plants are among the most intriguing species of angiosperms, yet they remain poorly understood. Mycoheterotrophic plants are found in several distinct lineages of angiosperms. Although there are many eudicot mycoheterotrophs (Gentianaceae, Ericaceae, and Polygalaceae) most mycoheterotrophic species are monocots (Leake, 1994). Monocot families with mycoheterotrophic representatives are Petrosaviaceae, Orchidaceae, Iridaceae, Corsiaceae, Triuridaceae, and Burmanniaceae. In contrast to green plants that fix carbon dioxide through photosynthesis, mycoheterotrophic plants obtain their organic carbon, partly or even exclusively, by digestion of fungal hyphae (Leake, 1994, 2004). The majority of mycoheterotrophs, including Burmanniaceae, are associated with arbuscular mycorrhizal fungi and "steal" carbon and other nutrients indirectly from green plants by hooking themselves into the mycorrhizal networks that link adjacent autotrophic plants (Imhof, 1999a, b, 2001; Leake,

\footnotetext{
${ }^{1}$ Manuscript received 28 February 2006; revision accepted 24 August 2006. The authors thank J. Moonen for his hospitality and constant support in the field and M. De Bont, Easyware N.V., and Kariboe for making an expedition to the Guianas possible; J. Anderson, S. Dessein, R. Ek, T. Franke, S. Graham, W. Hahn, R. Harwood, A. Ibañez, L. Janeway, A. Jaquemart, C. Jongkind, K.-P. Lo, R. Newell, R. Neyland, D. Nickrent, A. Poulsen, P. Ruijters, S. Ruysschaert, N. Sasidharan, I. Van Der Linden, M. Wapstra, and S.-Z. Yang for sending plant material or DNA extractions; and D. Zhang, T. Franke, P. Berry, and two anonymous reviewers for critical comments that greatly improved the manuscript. Processing of Haplothismia was done by N. Bhaskaran. The research was supported by the Institute for the Promotion of Innovation through Science and Technology in Flanders (IWT Vlaanderen, no. 31536 to V.M.). General financial support was provided by the K.U.Leuven (OT/05/35).

${ }^{5}$ Author for correspondence (e-mail: vincent.merckx@bio.kuleuven. be)
}

2004; Franke, 2006). In all mycoheterotrophs, this lifestyle has resulted in extreme vegetative reductions.

To study and understand the evolutionary history of the adaptations of mycoheterotrophic families to mycorrhizal fungi, we need to unravel their phylogenetic relationships and to identify the most related photosynthetic lineages. Despite our expanding knowledge of the systematic relationships in most plant families, very little is known about the evolutionary history of the mycoheterotrophic groups. First, there is the difficulty of including nonphotosynthetic mycoheterotrophs in plastid DNA analyses. Previous studies showed that some achlorophyllous species still contain amplifiable plastid DNA, but the resulting sequences have proved problematic in alignment and analyses due to elevated substitution rates (Chase et al., 1993; Nickrent et al., 1998; Caddick et al., 2002a). Furthermore, it seems highly probable that these high substitution rates are not restricted to the chloroplast genome but can also be expected in the nuclear and mitochondrial genome as shown for some parasitic lineages (Nickrent and Starr, 1994; Nickrent et al., 1998; Davis et al., 2004; Chase, 2004).

The third and perhaps main problem concerning the phylogenetics of mycoheterotrophic taxa is the scarcity of study material. Most mycoheterotrophs are small herbs found in the ground layer of dense, humid primary forest. They do not tolerate habitat disturbance and thus are largely restricted to more inaccessible locations. Collecting is further limited because ephemeral aboveground organs are produced only in the rainy season (Leake, 1994; Bidartondo, 2005). As a result, many mycoheterotrophic species are only known from the type collection, and some are presumed to be extinct. On the other hand, new species representing novel lineages are still being discovered (Zhang et al., 1999; Cheek et al., 2003; Woodward et al., in press). 


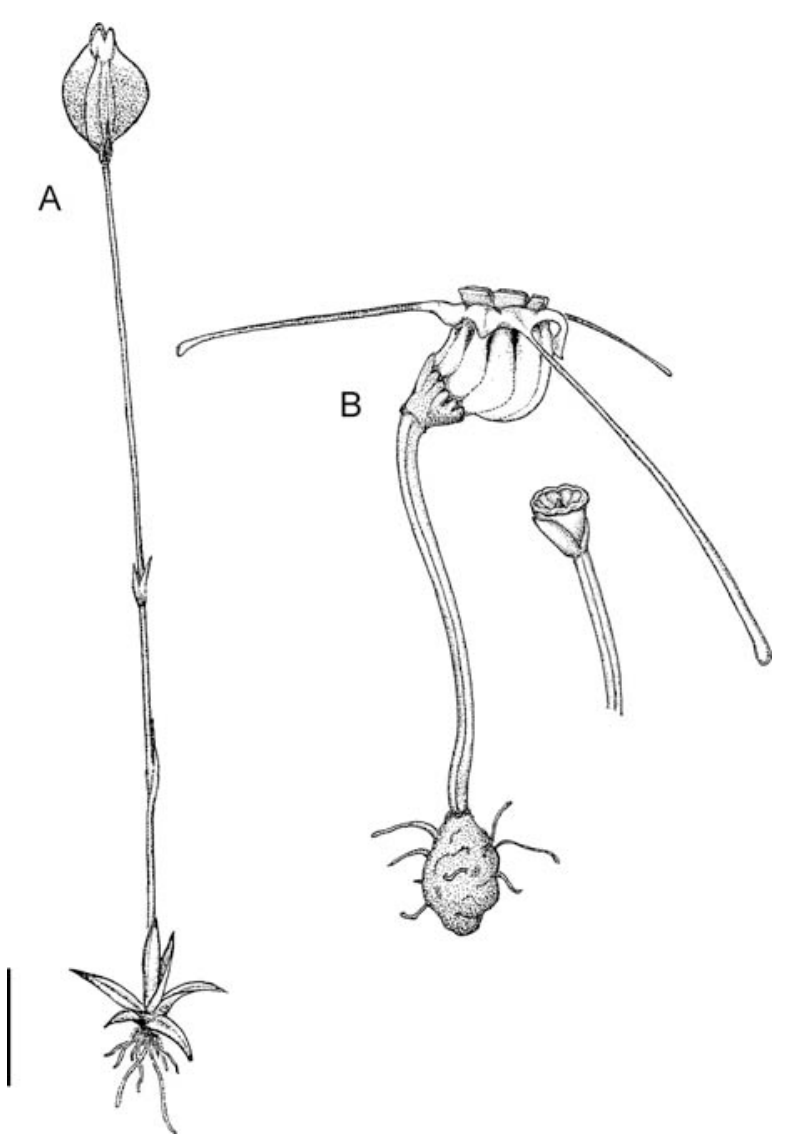

Fig. 1. Two species of Burmanniaceae that represent the two different tribes. (A) Burmannia bicolor Mart., tribe Burmannieae (Maas et al. 9673, Guyana). Note the reduced rosulate leaves. Although still green, this species is probably partly dependent on mycorrhizal fungi for its organic carbon. (B) Thismia panamensis (Standley) Jonk., tribe Thismieae (Aizprua 2946, Panama). After flowering, the perianth (with stamens and interstaminal lobes) drops off, leaving behind a cup-shaped fruit (shown on the right). Bar $=1 \mathrm{~cm}$.

In this study, we focused on the phylogeny of the mycoheterotrophic Burmanniaceae, a rather small family in which 14 genera and about 130 species have been described, although new species are discovered almost every year (e.g., Kiew, 1999; Zhang and Saunders, 1999, 2000; Liu et al., 2001; Thiele and Jordan, 2002; Yang et al., 2002; Maas-van de Kamer, 2003; Cheek, 2003; Franke, 2004; Franke et al., 2004; Sainge and Franke, 2005). Burmanniaceae are widespread in tropical areas of the world and some species can be found in warm temperate regions. The family consists of both achlorophyllous mycoheterotrophic and autotrophic green species (Fig. 1A). The latter are all part of the largest genus, Burmannia, and grow generally in more open habitats like wet grasslands and savannas. Although they have retained functional photosynthesis, most green-leaved Burmanniaceae have a certain degree of vegetative reduction, suggesting a partial dependence on mycorrhizal fungi. All achlorophyllous Burmanniaceae share strong modifications that are related to their mycoheterotrophic lifestyle: reduction of stomata, reduction of root hairs, reduction of leaves, and relatively well-developed underground parts (Jonker, 1938; Maas et al., 1986; Leake, 1994; Maas-van de Kamer, 1998).

Burmanniaceae consist of two, rather distinct lineages, that are regarded by most authors as different tribes, Burmannieae and Thismieae (Jonker, 1938; Stevenson and Laconte, 1995; Maas-van de Kamer, 1998; Cheek and Williams, 1999; Kiew, 1999; Caddick et al., 2002a, b; Yang et al., 2002; APG, 2003; Cheek, 2003; Sainge and Franke, 2005; Woodward et al., in press), but in some classifications Thismieae are considered as a separate family, the Thismiaceae (Chase et al., 1995, 2000; Takhtajan, 1997; APG, 1998; Caddick et al., 2000a, b; Neyland, 2002; Thiele and Jordan, 2002; Neyland and Hennigan, 2003).

Burmannieae (or Burmanniaceae sensu stricto) are characterized by a persistent perianth and three stamens and contain two pantropical genera: Burmannia L. (about 60 species) and Gymnosiphon Bl. (about 20 species). It is noteworthy that all species in both genera are limited to one continent, and they are often difficult to distinguish (Jonker, 1938). The remaining seven Burmannieae genera (Apteria Nutt., Hexapterella Urb., Campylosiphon Benth., Cymbocarpa Miers, Dictyostega Miers, Marthella Urb., and Miersiella Urb.) are restricted to the neotropics and contain only one or two species each (Maasvan de Kamer, 1998).

The tribe Thismieae (or Thismiaceae) consists of highly reduced mycoheterotrophic herbs and differs from Burmannieae by a circumscissile perianth (Fig. 1B) and the presence of six stamens (except for Oxygyne with three stamens). All species of this tribe are remarkably rare, and some extreme and unexplained biogeographic disjunctions can be found within some genera. Five Thismieae genera are currently known. The largest genus, Thismia Griff. (about 35 species), inhabits the rain forests of South America and Asia, although a few species extend into more temperate regions in Australia, New Zealand, Japan, and the upper midwestern USA. Afrothismia Schltr. (nine species) is restricted to the tropical rain forests of Africa and the monospecific genus Haplothismia Airy Shaw is only known from a few collections at the type locality in the Western Ghats (India; Airy Shaw, 1952; Sasidharan and Sujanapal, 2000). Two species of the intriguing genus Oxygyne Schltr. are known from Cameroon and two from Japan (Schlechter, 1906; Abe and Akasawa, 1989; Maas-van de Kamer, 1998). In April 2005 a single specimen of a new Thismieae genus, Tiputinia, was collected in Amazonian Ecuador (Woodward et al., in press). This discovery stresses once again our incomplete knowledge of this group.

Because the mycoheterotrophic habit of Burmanniaceae has resulted in extreme vegetative reductions, subdivision of the family has always been problematic. The only worldwide monographic treatment of the Burmanniaceae is by Jonker (1938). Although many new species have been discovered since, all of Jonker's nine Burmannieae genera have been maintained. Jonker's subdivision of the Burmannieae into the subtribes Euburmannieae (Burmannia, Campylosiphon, and Hexapterella) and Apterieae (Apteria, Cymbocarpa, Dictyostega, Gymnosiphon, Marthella, and Miersiella-) is based on differences in placentation. Rübsamen (1980), however, showed that this character is not as strictly distributed as Jonker supposed, and these subtribes were therefore not followed in subsequent classifications (Maas et al., 1986).

In the Thismieae, Jonker distinguished seven genera. Four of them were combined into Thismia by subsequent authors (Stone, 1980; Maas et al., 1986; Maas-van de Kamer, 1998). The genus Haplothismia was described by Airy Shaw in 1952. He created a new tribe for this peculiar monotypic genus, the Haplothismieae, but the genus was later included in the 
Thismieae by Maas et al. (1986). This remarkable genus was presumed extinct until October 2000 when a second collection of Haplothismia exannulata was made, 49 years after the type collection (Sasidharan and Sujanapal, 2000). Jonker's subdivision of the Thismieae in the subtribes Thismiinae (six stamens; Thismia, Afrothismia, and consequently also Haplothismia and Tiputinia) and Oxygyninae (three stamens; Oxygyne) is still used by most authors.

The affinities of Burmanniaceae have been problematical for a long time, mainly because many vegetative characters are absent in most members of the family. As a result, Burmanniaceae have been linked with various families such as Orchidaceae, Amaryllidaceae, and Iridaceae (see Maas et al., 1986 for a full overview). The use of molecular data, however, has shed new light on the position of Burmanniaceae among the monocots. In the $r b c L$ study of Chase et al. (1993), an autotrophic Burmannia species is sister to the Alismataceae in their 475 taxa analysis but was removed from the 499 taxa analysis because it was "highly sequence divergent from all other taxa" (Chase et al., 1993, p. 536). In a subsequent phylogenetic analysis of 172 monocot $r b c L$ sequences, the same Burmannia species was sister to Dioscorea and Tacca (Chase et al., 1995). All succeeding molecular analyses with additional data and sampling recovered a monophyletic Burmanniaceae sister to Dioscoreaceae, and therefore part of Dioscoreales (Caddick et al., 2000b, 2002a, b; Soltis et al., 2000; Davis et al., 2004; APG, 1998, 2003). Only the 26S rDNA analyses by Neyland (2002) and Neyland and Hennigan (2003) revealed a different hypothesis, with Burmanniaceae (and Corsiaceae) sister to almost all other monocot groups. In all studies mentioned, sampling of Burmanniaceae was insufficient to clarify any relations within the family.

The placement of Burmanniaceae in Dioscoreales is well supported by molecular data, but remains poorly understood. The Dioscoreales are a morphological heterogeneous order, and the three recognized families, Nartheciaceae, Burmanniaceae, and Dioscoreaceae, do not seem to have a lot in common. Few convincing morphological synapomorphies have been found for the current delimitation of Dioscoreales (Caddick et al., 2000a, 2002).

Because a phylogenetic hypothesis with an extensive sampling of Burmanniaceae can help us to better understand the evolutionary history of this puzzling family, we used molecular data from 44 different Burmanniaceae species from nine genera to investigate both family membership and generic relationships. Many species and genera are sampled here for the first time, including species of the extremely rare genera Afrothismia and Haplothismia. Due to problems associated with the use of plastid DNA data from achlorophyllous taxa in phylogenetic analyses, we decided to use sequence data from the nuclear (18S rNDA) and mitochondrial (nadl $b-c$ intron) genome. Nuclear gene sequences, $18 \mathrm{~S}$ rDNA in particular, have often been used in monocot systematics (Bharathan and Zimmer, 1995; Soltis et al., 1997; Chase et al., 2000; Chase, 2004). Although mostly congruent with plastid data, $18 \mathrm{~S}$ rDNA sequences have proven to contain less phylogenetic signal in comparison to plastid DNA due to low sequence divergence (Soltis et al., 1997). However, 18S rDNA proved a good source of phylogenetic information in Dioscoreales (Caddick et al., 2002a). So far only a few studies have used mitochondrial DNA sequences to infer monocot relationships (Davis et al., 2004; Petersen et al., 2005). These analyses have shown that AtpA and $c o b$ data are significantly incongruent with plastid data. At a lower taxonomic level nadl $b$ - $c$ has been successfully used for phylogenetic reconstruction in Orchidaceae, although resolution of the obtained topology was rather low (Freudenstein and Chase, 2001).

The gaps present in the mitochondrial sequences were used as an extra data source, and we report on their phylogenetic signal. Based on the resulting topology, we studied the evolutionary pattern of the loss of photosynthesis in Dioscoreales.

Additionally, we performed a relative rates test on the nuclear $18 \mathrm{~S}$ rDNA data. Previous studies on various holoparasitic lineages reported increased rates of molecular evolution of 18S rDNA (Nickrent and Starr, 1994; Nickrent et al., 1998), but similar tests are still lacking for mycoheterotrophic groups. Elevated substitution rates and correlated long phylogenetic branches can be expected in achlorophyllous taxa leading to possible long-branch attraction (LBA) artifacts. To detect whether LBA influenced our analyses, the data were analyzed both under the maximum parsimony and Bayesian inference optimality criteria, and a LBA test described by Bergsten (2005) was performed.

\section{MATERIALS AND METHODS}

Plant material and sampling — The appendix lists all taxa included in this study with voucher information, GenBank accession numbers, and geographic origin. Apart from Burmanniaceae, multiple Dioscoreaceae taxa were used in this study. These include the genera Dioscorea and Stenomeris, but not Avetra and Trichopus because we were unable to obtain mitochondrial nadl $b$ - $c$ intron sequences for these genera. In a preliminary analysis of 18S rDNA sequences of Dioscoreales, Avetra and Trichopus were sister to Dioscorea in a topology that resembles the 18S rDNA topology presented here (Merckx et al., 2005). Moreover, the same placement of Trichopus was recovered by Caddick et al. (2002a). Therefore, we are confident that their absence does not affect the ingroup topology. Taxa of Nartheciaceae were used as outgroup based on previous phylogenetic analyses of Dioscoreales (Caddick et al., 2000b, 2002a).

DNA extraction, PCR amplification, and sequencing-DNA was extracted from silica-dried and herbarium material with the Puregene DNA extraction kit (Gentra Systems, Landgraaf, the Netherlands) following the manufacturer's instructions. Amplification of the $18 \mathrm{~S}$ rDNA region was made with primers NS1, NS2, NS3, NS4, NS5, and NS8 (White et al., 1990) under the following conditions: $1 \mathrm{~min}$ at $94^{\circ} \mathrm{C}$ followed by 30 cycles of $30 \mathrm{~s}$ at $94^{\circ} \mathrm{C}$, $30 \mathrm{~s}$ at $44^{\circ} \mathrm{C}$, and $1 \mathrm{~min}$ at $72^{\circ} \mathrm{C}$, followed by $7 \mathrm{~min}$ at $72^{\circ} \mathrm{C}$. The nadl $\mathrm{b}-\mathrm{c}$ intron was amplified with primers nad1-B and nad1-C from Demesure et al. (1995). For some taxa, newly designed and internal primers were used to obtain an amplification product: nadBur-F (5' CGG ATG TTC CCC TAA CCC AAC $\left.3^{\prime}\right)$, nadBur-MR (5' CAC CTA CAG CCC TTT CCA CTG $\left.3^{\prime}\right)$, nadBur-MF (5' CAG AGG AAA GGG CTG TAG GTG 3') and nadBur-R (5' GGG AAC AAG GGA ATA CCG GAC $3^{\prime}$ ). They were amplified with $4 \mathrm{~min}$ at $94^{\circ} \mathrm{C}$, followed by 30 cycles of $30 \mathrm{~s}$ at $94^{\circ} \mathrm{C}, 30 \mathrm{~s}$ at $52^{\circ} \mathrm{C}$ and $1.5 \mathrm{~min}$ at $72^{\circ} \mathrm{C}$, followed by $7 \mathrm{~min}$ at $72^{\circ} \mathrm{C}$. For some reactions, multiple amplification products were obtained with this method. In all cases, specific amplification products could be obtained with a touchdown PCR in which the main 30 cycles were replaced by 2 cycles with an annealing temperature of $60.5^{\circ} \mathrm{C}$, then 19 cycles with annealing temperature $50.5^{\circ} \mathrm{C}$ declining $1^{\circ} \mathrm{C}$ every cycle, followed by 10 cycles with annealing temperature $41.5^{\circ} \mathrm{C}$. The PCR reaction mixture was cleaned using a Nucleospin Extraction II Kit (Machery-Nagel, Düren, Germany) according to the manufacturer's instructions. Sequencing was done on an ABI 310 Genetic Analyzer (Applied Biosystems, Foster City, California, USA). Some samples were sequenced by the Macrogen sequencing facilities (Seoul, South Korea).

Sequence assembly, alignment, and gap coding — Assembly and editing of sequences was conducted using Staden et al. (1998). Sequences were manually aligned with MacClade 4.04 (Maddison and Maddison, 2001). Because of low sequence divergence, alignment was straightforward for the $18 \mathrm{~S}$ rDNA 
sequences. For some regions of the nadl $b$-c intron data set alignment was ambiguous due to high sequence divergence (especially for Thismieae taxa). Those regions were excluded from the data matrix. Most regions in the nadl $b-c$ intron, however, were highly conserved and easy to align, although numerous and sometimes very long deletions made the insertions of more than 600 different gaps necessary. All gaps were coded according to the "simple indel coding" method (SIC) described by Simmons and Ochoterena (2000) as implemented in the SeqState software (Müller, 2005). Although the "complex indel coding" method generates more data, we specifically chose to use SIC because this method produces binary data, which can be analyzed with MrBayes version 3.1 (described next)

Phylogenetic analyses-Phylogenetic analyses of relationships were conducted using both maximum parsimony (MP) and Bayesian inference (BI) optimality criteria. The two sequenced DNA regions were first analyzed separately and then combined. To infer the phylogenetic utility of the coded gaps, a separate MP and BI analysis on the SIC characters was also conducted. MP analyses were performed using PAUP* version $4 \mathrm{~b} 10$ (Swofford, 2002). A set of most parsimonious trees from the different data sets were obtained through a heuristic search employing random stepwise addition of taxa with 1000 replicates under the tree-bisection-reconnection (TBR) branch swapping, saving multiple trees (MULTREES) at each step. Bootstrap support values for individual clades were obtained by heuristic searches of 100 replicates with TBR in effect on 1000 replicates of the data. All MP analyses supported a rather surprising relationship between Thismieae and Tacca. Given the long branches observed in Thismieae, we suspected that this affinity could be the result of a long-branch attraction artifact. To evaluate this possibility, we followed the strategy described by Bergsten (2005) and re-ran the MP analyses: (1) without the outgroup (Nartheciaceae), (2) without Thismieae, and (3) without Tacca.

The substitution model for each DNA region was selected with Modeltest v3.06 (Posada and Crandall, 1998) under the Akaike information criterion (AIC). Modeltest selected the GTR $+\mathrm{I}+\mathrm{G}$ model of evolution for both the $18 \mathrm{~S}$ rDNA data and the nadl $b-c$ intron data (without SIC). For analyzing the SIC data under BI, we used the Restriction Site Model of MrBayes 3.1, as recommended by the authors (Ronquist et al., 2005). In the combined BI analysis (nadl $b-c+$ SIC and 18S rDNA + nadl $b-c+$ SIC) a mixed-model approach was used. The combined data were partitioned, and the same models of evolution were used on the partitions as selected for the single analyses: GTR $+\mathrm{I}+\mathrm{G}$ for $18 \mathrm{~S}$ rDNA and nadl $b-c$ and Restriction Site Model for SIC data. Bayesian analyses were conducted with MrBayes 3.1 (Huelsenbeck and Ronquist, 2001; Ronquist and Huelsenbeck, 2003) on an Apple Xserve G5 computer. Four Markov chains starting with a random tree were run simultaneously for one million generations, sampling trees at every 100th generation. The first 2500 sampled trees (25\%) were regarded as "burn in" and discarded. A majority rule tree of the remaining trees was calculated with PAUP* $4 \mathrm{~b} 10$.

Bayesian relative rates test-We conducted a Bayesian relative rates test on the 18S rDNA data according to the method described by Wilcox et al. (2004). The posterior probability distribution of lengths for all branches was obtained by saving branch lengths for each sampled tree during the Bayesian analysis. Because all analyses clearly recovered a monophyletic ingroup, we used all sampled outgroup taxa to identify the most recent common ancestor (MRCA) of the ingroup. For each sampled tree, the distance from the MRCA to each of the terminal taxa was calculated with Cadence v.1 (Wilcox et al., 2004). Data plotting and calculation of the $95 \%$ Bayesian posterior probability intervals were done with Excel 2004 for Mac version 11.2.3 (Microsoft, Redmond, Washington, USA). If the interval around an estimated distance from the MRCA to a taxon did not overlap with the confidence interval of another taxon, we concluded that the rate of evolution between these two taxa differed significantly.

Because the fastest evolving regions of the nadl b-c data were omitted from the analyses because alignment was not possible, we were not able to conduct a relative rates test on the mitochondrial data.

\section{RESULTS}

$18 S \mathrm{rDNA}$ - In total, 72 taxa are included in the 18S rDNA data set, including 60 taxa of Burmanniaceae. The final aligned data matrix contains 1723 characters with 314 (18\%) parsimony informative characters. Overall, the 18S rDNA MP and BI analyses recover well-resolved topologies (Fig. 2). The tree statistics are given in Table 1 . The exclusion of the outgroup, Thismieae or Tacca in the MP analyses did not change the relationships between the remaining ingroup taxa. Some minor differences between the MP and BI analyses are present, but these only involve branches for which no bootstrap support was obtained. Generally, the Bayesian inference of phylogeny for $18 \mathrm{~S}$ rDNA is more resolved and more strongly supported than the parsimony bootstrap analysis. The ingroup (Burmanniaceae and Dioscoreaceae) is resolved as monophyletic $(98 \%$ bootstrap percentage [BS], $100 \%$ posterior probability [PP]), but neither Burmanniaceae nor Dioscoreaceae are monophyletic herein. All representatives of tribe Burmannieae are found in a monophyletic clade $(94 \% \mathrm{BS}$, $100 \% \mathrm{PP}$ ), sister to the remaining ingroup taxa (Burmanniaceae tribe Thismieae and Dioscoreaceae). Burmannieae consist of a basal polytomy with a poorly supported HexapterellaGymnosiphon-Cymbocarpa clade (52\% BS, 88\% PP) in which Hexapterella is resolved as monophyletic (99\% BS, 100\% PP) and as sister to Gymnosiphon-Cymbocarpa with low bootstrap support but with moderate posterior probability (95\% PP). The two Cymbocarpa species are resolved as monophyletic with maximum support (100\% BS, 100\% PP) and included in Gymnosiphon, making this genus paraphyletic. Also part of the basal Burmannieae polytomy is a weak to moderately supported (76\% BS, 77\% PP) clade with Dictyostega as sister to all species of Burmannia except for $B$. densiflora and $B$. congesta, which share an unresolved position at the base of Burmannieae. There is no bootstrap support and only weak posterior probability (86\%) for the placement of Dictyostega sister to Burmannia (without B. congesta and B. densiflora). This Burmannia clade lacks bootstrap support and has only a weak Bayesian posterior probability ( $86 \% \mathrm{PP})$. Within this clade, all species except $B$. longifolia and $B$. sphagnoides are part of a maximally supported clade (100\% BS, $100 \%$ PP). This group contains a few clades with significant support: $B$. coelestis-B. juncea-B. disticha (89\% BS, $100 \%$ PP), $B$. wallichii-B. itoana (92\% BS, $100 \%$ PP), B. alba-B. biflora (92\% BS, 100\% PP), B. flava-B. stuebelii (93\% BS, 100\% PP), and $B$. capitata-B. damazii $(98 \% \mathrm{BS}, 100 \% \mathrm{PP})$. The fifth clade present in the unresolved Burmannieae consists of the two included Apteria specimens (100\% BS, $100 \%$ PP).

The other tribe of Burmanniaceae, Thismieae, is monophyletic (92\% BS, $100 \%$ PP) and sister to the four sampled Tacca species that group together with moderate to high support $(76 \%$ BS, $100 \%$ PP). Support for the Thismieae-Tacca relationship is moderate (94\% BS, 90\% PP). Within Thismieae, all Asiatic Thismia species are part of a moderately supported clade $(82 \%$ BS, $100 \%$ PP), while all other Thismieae taxa are present in a clade with no bootstrap and only weak posterior probability (67\%). Remarkably, the neotropical Thismia panamensis is part of this clade, sister to Afrothismia hydra (87\% BS, 52\% PP). A strongly supported polytomy, with Dioscorea and Stenomeris, is sister to the Thismieae-Tacca clade.

nad1 b-c intron-The nadl $b$ - $c$ dataset had 2200 characters of which $410(19 \%)$ were parsimony-informative. The coded gaps added 606 characters with 202 (33\%) parsimonyinformative characters. Recovery of the nadl $b$-c sequence of Afrothismia hydra was unsuccessful and therefore this species in not present in the nadl $b$-c topologies. As a result, data of 71 


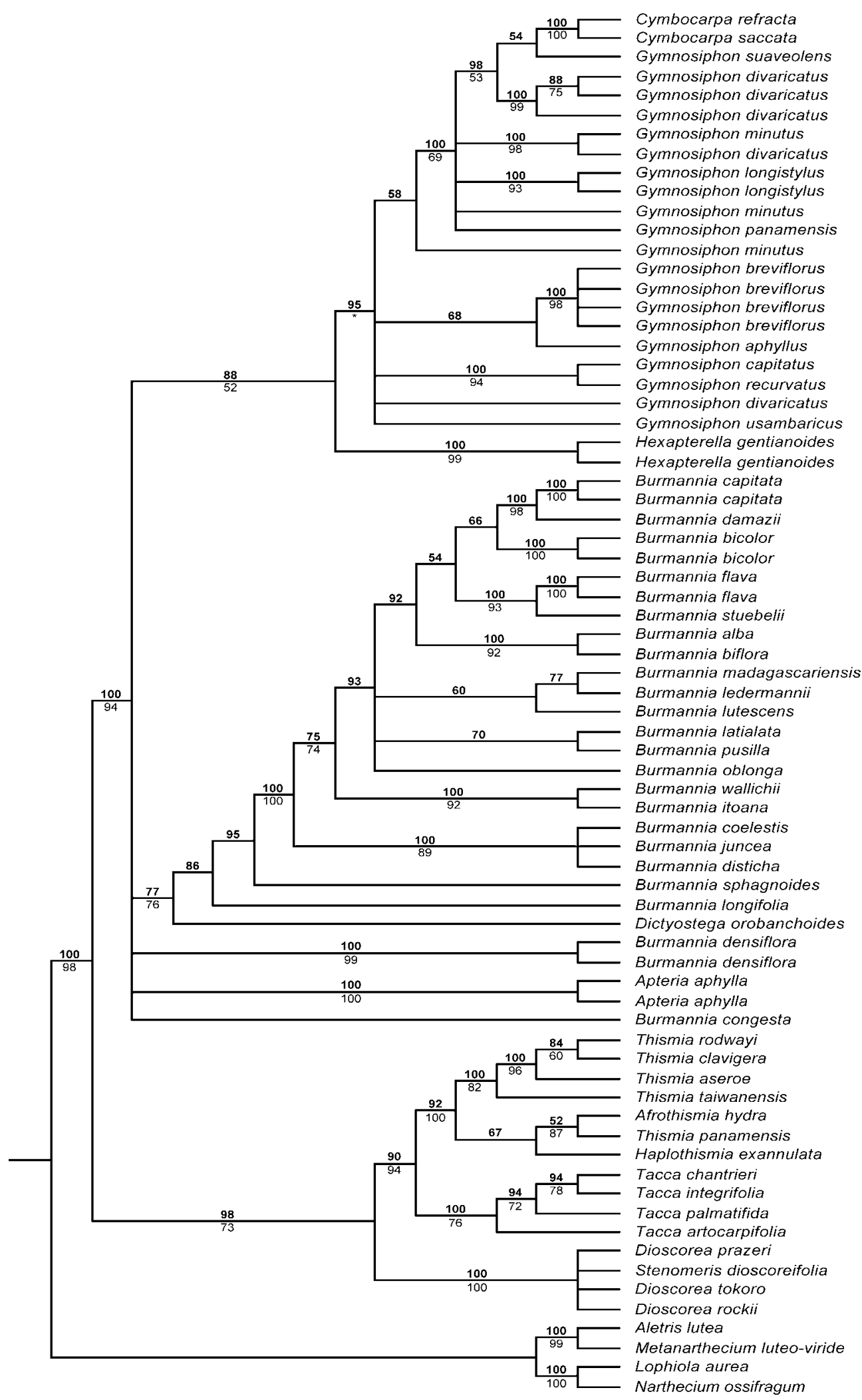

Fig. 2. Majority rule tree of the Bayesian analysis of the 18S rDNA data. Bold numbers above branches are posterior probabilities; numbers below branches indicate bootstrap support $(>50 \%)$. Branches present in the strict consensus maximum parsimony tree for which no bootstrap support was obtained are marked with an asterisk. 
TABLE 1. Consistency (CI) and retention (RI) indices for the most parsimonious trees of each data set.

\begin{tabular}{lcc}
\hline \hline \multicolumn{1}{c}{ Data set } & CI & RI \\
\hline 18S rDNA & 0.44 & 0.71 \\
nadl $b$ - $c$ bases only & 0.77 & 0.84 \\
nadl $b$ - $c$ indels only & 0.72 & 0.77 \\
nadl $b$ - + indels & 0.74 & 0.81 \\
Combined data & 0.62 & 0.74 \\
\hline
\end{tabular}

taxa including 59 Burmanniaceae were available for the nadl $b-c$ analyses.

All clades found in the strict consensus of the MP analysis are present in the BI majority rule tree, although the latter is better resolved (Fig. 3A). Again, deleting the outgroup, Thismieae or Tacca had no influence on the placement of the remaining ingroup taxa. As in the $18 \mathrm{~S}$ rDNA analysis, the ingroup is monophyletic ( $100 \% \mathrm{BS}, 99 \% \mathrm{PP})$, and the affinity of the Thismieae with Tacca is also moderately supported (85\% BS, 95\% PP). Moderate support for the monophyly of the Thismieae is obtained (75\% BS, 95\% PP). Given the absence of Afrothismia, the same relationships in Thismieae are recovered as in the $18 \mathrm{~S}$ rDNA analyses. Unlike the $18 \mathrm{~S}$ rDNA analyses, the nadl $b$-c topologies show a sister group relationship of Dioscorea-Stenomeris and Burmannieae that is weakly supported by bootstrap (66\%) and moderately by posterior probability (93\%). The Burmannieae are a highly supported clade $(97 \%$ BS, $100 \%$ PP). It generally contains the same major clades as in the $18 \mathrm{~S}$ rDNA topologies. Identical with $18 \mathrm{~S}$ rDNA data, these clades are part of all large polytomies in the MP analyses. The BI topologies, however, are fully resolved concerning these relationships (Fig. 3A). Starting from the top, there is moderate support for the affinity between Hexapterella and Gymnosiphon-Cymbocarpa $(82 \%$ BS, 97\% PP) and high support for the monophyly of both clades (94\% BS, 98\% PP for Hexapterella and 97\% BS, 98\% PP for Gymnosiphon-Cymbocarpa). Within the GymnosiphonCymbocarpa clade, the position of Cymbocarpa saccata close to Gymnosiphon recurvatus and not to Cymbocarpa refracta is a noteworthy difference with the $18 \mathrm{~S}$ rDNA analyses. Unique to the BI tree are the position of Dictyostega sister to Apteria (58\% PP) and the affinity of Burmannia congesta with Burmannia densiflora (99\% PP). All remaining Burmannia species are resolved in a clade, sister to the other Burmannieae with low bootstrap $(60 \% \mathrm{BS})$ and moderate posterior probability (94\% PP). In this clade, Burmannia longifolia is not at the base as in the $18 \mathrm{~S}$ rDNA tree but rather linked with other green-leaved Burmannia species from Asia: B. juncea, $B$. coelestis, and $B$. disticha. Another major difference from $18 \mathrm{~S}$ rDNA in this clade is the placement of the $B$. capitata- $B$. damazii clade, which is found in a basal position and not linked with the other neotropical species.

Analysis of the 202 parsimony-informative indels alone revealed fairly well-resolved topologies (Fig. 3B). Consistency and retention indices of the trees based on the data with or without the SIC data are given in Table 1. No major differences between the strict consensus MP tree and the majority rule BI tree were detected. In general, the obtained topology is congruent with the nadl $b-c+$ SIC analyses, although the resolution at a lower taxonomic level is considerably lower in the topology based on SIC data alone.
Combined data-The combined data set contained 4529 characters with 944 (21\%) parsimony-informative characters. Because the inclusion of Afrothismia hydra, from which only $18 \mathrm{~S}$ rDNA data are present, did not influence the topology or the support values, this species was retained in the analysis. The exclusion of the outgroup, Thismieae or Tacca did not change the overall topology of the MP tree. The BI analysis of the combined data produced a tree with more resolution than the MP analysis, and both topologies were generally congruent with each other (Fig. 4). The only well-supported difference between the MP and the BI analysis was found in the placement of Cymbocarpa saccata. In the MP analysis, $C$. saccata was placed sister to C. refracta with $86 \%$ BS, while the $\mathrm{BI}$ analysis revealed an affinity with $G$. recurvatus. Some other minor differences were observed between the strict consensus MP tree and the majority rule BI tree, but these involved only clades with no BS.

The monophyly of the ingroup (Burmanniaceae and Dioscoreaceae) received maximum support (100\% BS, $100 \%$ $\mathrm{PP})$. Consistent with the separate gene analyses, the ingroup contains three clades namely Thismieae-Tacca, DioscoreaStenomeris, and Burmannieae. All three clades show maximum branch support $(100 \% \mathrm{BS}, 100 \% \mathrm{PP})$. In the BI analysis the Thismieae-Tacca clade is sister to the two other clades as in the nadl $b-c$ analysis. There is, however, no bootstrap and only weak posterior probability support $(89 \% \mathrm{PP})$ for this placement, which is considerably lower than the support obtained with the nadl $b$-c data alone. In the Thismieae-Tacca clade, both Thismieae and Tacca are resolved as monophyletic with high support. The relationships obtained in Thismieae are congruent with those obtained by the separate analyses and for almost all branches a considerably higher branch support was obtained. The resulting Burmannieae clade is almost identical with the separate nadl $b$-c analysis. Only the placement of the Burmannia congesta-Burmannia densiflora clade and Dictyostega differs, but no significant bootstrap support was obtained for the placement of these clades.

Relative rates test-The Bayesian relative rate test of the $18 \mathrm{~S}$ rDNA data (Fig. 5) reveals considerable variation in rates of molecular evolution among the different ingroup lineages. Relative to the included Dioscoreaceae taxa (Dioscorea, Stenomeris and Tacca), which show no mutual difference of substitution rates, several Burmanniaceae taxa share a significant elevated substitution rate. The Bayesian 95\% posterior probability intervals of all included Thismieae and all Apteria, Cymbocarpa, Dictyostega; furthermore, Burmannia samples do not overlap with those of Dioscoreaceae, and therefore $18 \mathrm{~S}$ rDNA has evolved significantly faster in those taxa. In Thismia and Afrothismia, the rate differences relative to Dioscoreaceae are particularly extreme. In contrast to this, the rate of molecular evolution of all Gymnosiphon, Hexapterella, and some Burmannia species is not significantly different from Dioscoreaceae.

\section{DISCUSSION}

Relative rates - The phylogenetic resolution obtained with $18 \mathrm{~S}$ rDNA (Fig. 2) is relatively high, as previously shown in Dioscoreales by Caddick et al. (2002a). This is remarkable because $18 \mathrm{~S}$ rDNA is generally regarded as highly conserved and mostly used at an interfamilial rather than intergeneric or 

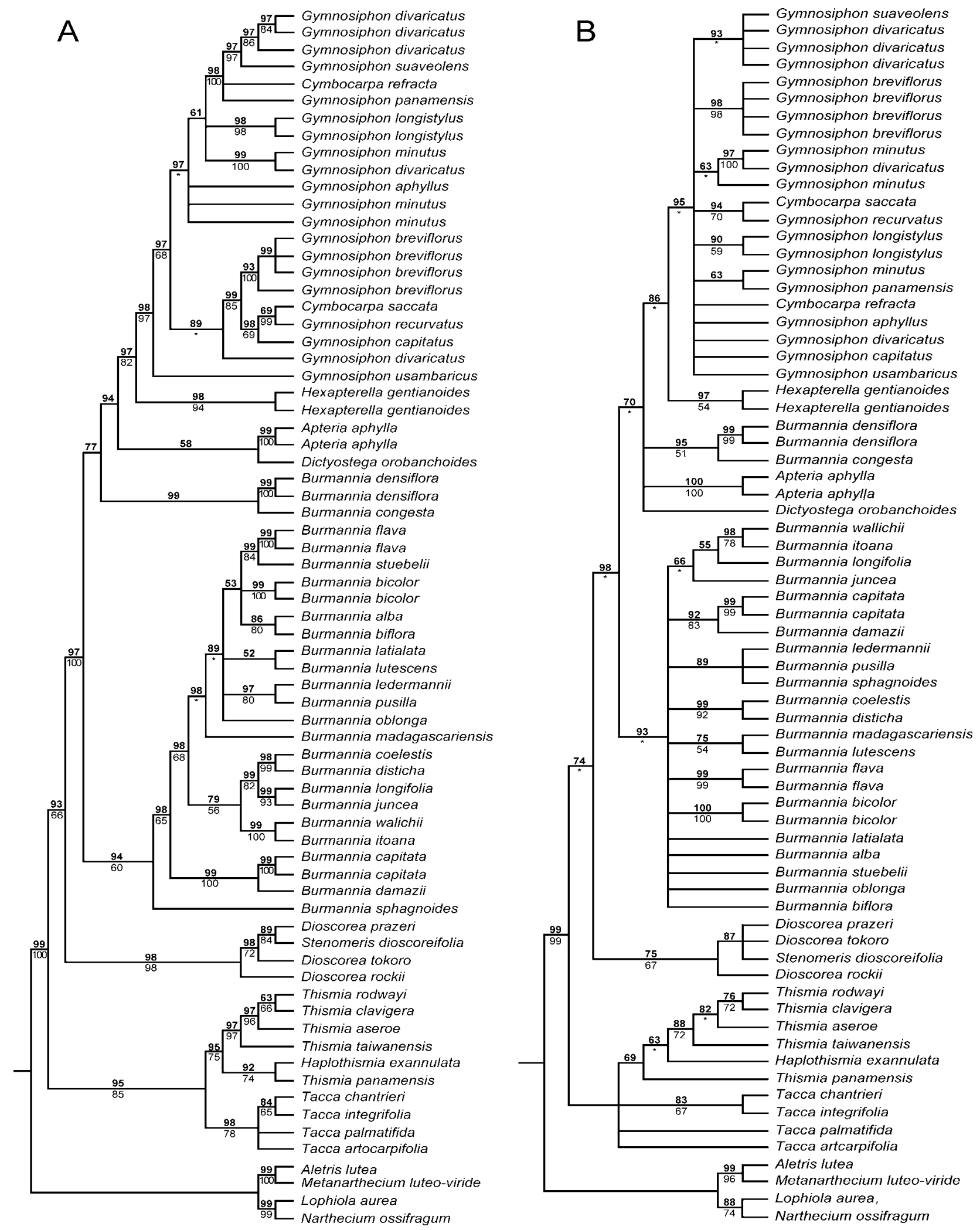

Fig. 3. Phylogenetic results based on $n a d l b$-c data. (A) Majority rule tree of the Bayesian analysis of the nadl $b$-c data with simple indel coding. (B) Majority rule tree of the Bayesian analysis of the simple indel coding data alone. Bold numbers above branches are posterior probabilities; numbers below the branches show bootstrap support $(>50 \%)$. Branches that are present in the strict consensus MP tree without bootstrap support are indicated with an asterisk. 


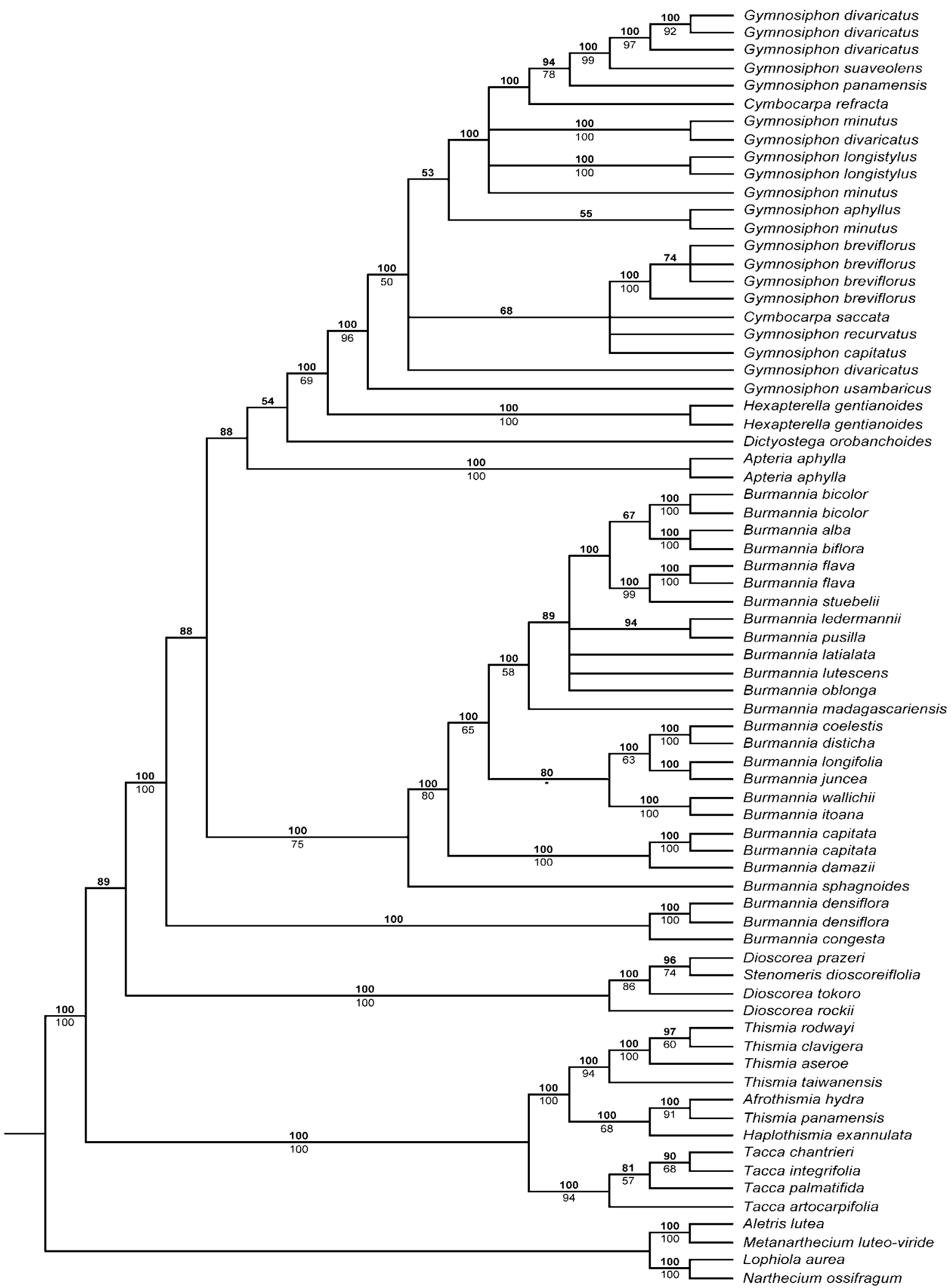

Fig. 4. Majority rule tree of the Bayesian analysis of the combined data (18S rDNA + nadl $b-c+$ SIC). Bold numbers above branches are posterior probabilities; numbers below branches indicate bootstrap support $(>50 \%)$. Branches present in the strict consensus maximum parsimony tree for which no bootstrap support was obtained are marked with an asterisk. 


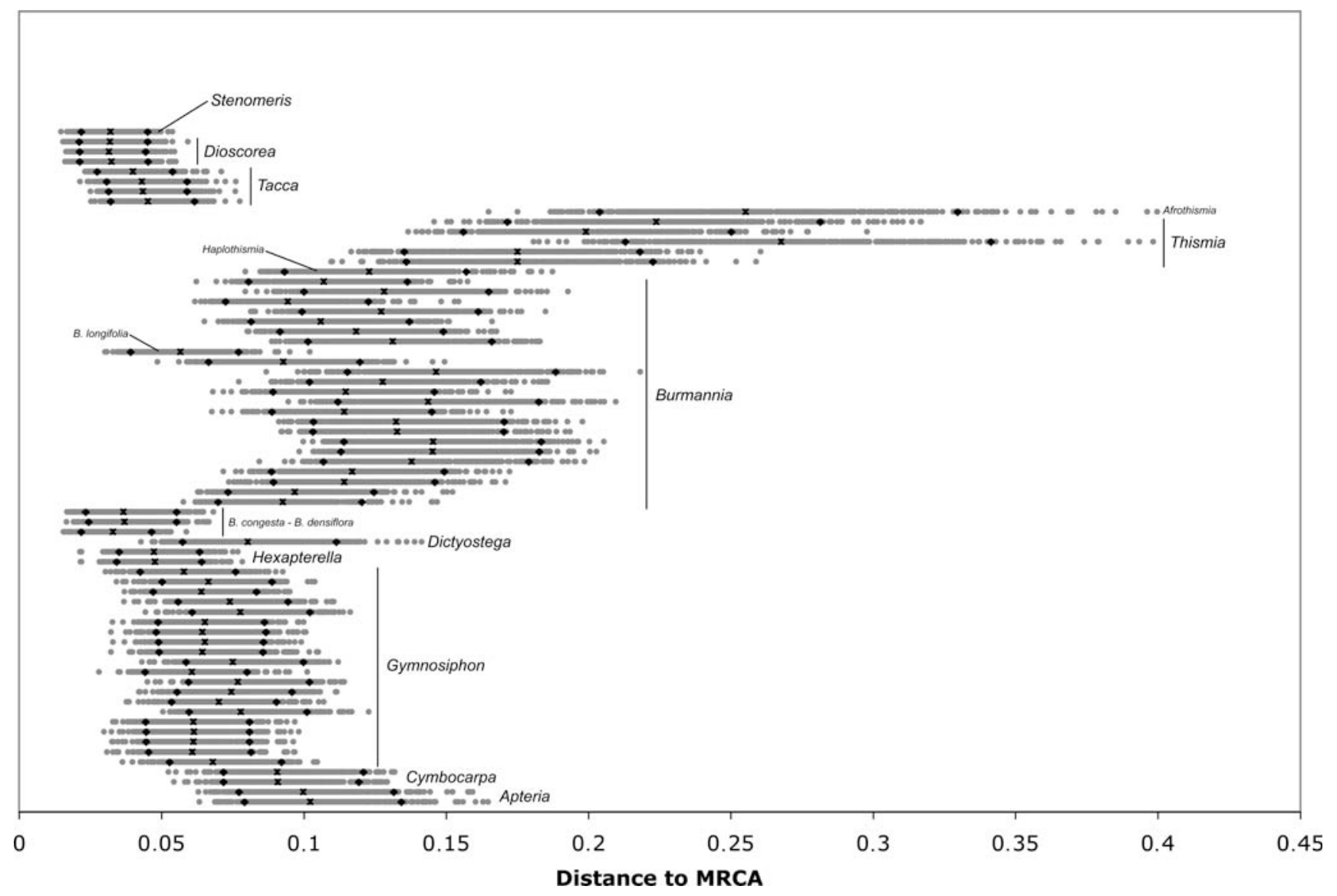

Fig. 5. Distribution of branch lengths from the most recent common ancestor (MRCA) of the included Burmanniaceae and Dioscoreaceae. Crosses represent the mean branch lengths. Squares delimit the confidence intervals in which $95 \%$ of the observed distances fall.

interspecific level (Hamby and Zimmer, 1988; Soltis and Soltis, 1998). In most cases, $18 \mathrm{~S}$ rDNA evolves at only onethird to one-half the rate of $r b c L$. Within some groups, such as Orchidaceae (Cameron and Chase, 2000) and holoparasitic angiosperms (Nickrent and Starr, 1994; Nickrent et al., 1998), higher rates are observed. Not unexpectedly, our results show that the substitution rate of $18 \mathrm{~S}$ rDNA is significantly higher in many Burmanniaceae taxa relative to Dioscoreaceae (Fig. 5). In particular, Thismia and Afrothismia have exceptionally increased rates. These two genera probably share the most extreme vegetative reductions compared to the other included Burmanniaceae taxa. However, rate accelerations and vegetative reduction does not seem to be correlated, because many green-leaved Burmannia species have significantly increased rates relative to Dioscoreaceae, while the rates of all Gymnosiphon and Hexapterella species do not significantly differ from Dioscoreaceae. Our results indicate that rate increases may have occurred prior to the loss of photosynthesis, because rate increases were observed in many green-leaved Burmannia species. Furthermore, the loss of chlorophyll does not imply $18 \mathrm{~S}$ rDNA rate accelerations: all Gymnosiphon species are achlorophyllous, but no significant rate differences relative to Dioscoreaceae have been measured here.

The underlying causes of accelerated substitution rates are unknown, but numerous hypotheses have been proposed. Small effective population size and correlated genetic bottlenecks may be involved (Wu and Li, 1985; Nickrent and Starr, 1994).
All Thismeae species have extremely small, often widely scattered populations (e.g., Franke et al., 2004; Cheek, 2003). These population characteristics do not apply, however, to some Burmannia species, which also have accelerated rates yet are present in relatively large, widespread populations. Consequently, the effective population size is certainly not solely responsible for the higher substitution rates in some Burmanniaceae.

Phylogenetic value of indels-The presence of multiple and overlapping gaps in the aligned nadl $b-c$ sequences made gapcoding straightforward. Although we used a very simple and conservative presence/absence coding method, both MP and BI analyses of the gap data proved that the phylogenetic signal of these data are significant and add important phylogenetic information to the analyses. The trees recovered by the analyses of the SIC data contain almost all major clades that are present in the other analyses (Fig. 3B). Although the consistency index (CI) and retention index (RI) of the MP trees based on SIC data alone are lower than those of the trees based solely on the nadl $b$-c nucleotide data, both RI and CI of the SIC trees are relatively high compared to the $18 \mathrm{~S}$ rDNA trees (Table 1). As demonstrated previously by Freudenstein and Chase (2001), these results show that $n a d l b$ - $c$ is a very useful mitochondrial DNA region for phylogenetic inference at a low taxonomic level, particularly if the omnipresent gaps are used as an extra source of data. Finally, it is interesting to note that 
the SIC data analyzed under the BI optimality criterion returned a tree highly similar and slightly better resolved than the MP analysis. Although gap-coding data are often used in phylogenetic MP analyses, the gap-coding characters are mostly omitted when the analyses are repeated under the BI criterion. Our results show that inclusion of binary gap data under the restriction site model is a powerful and reliable approach to use this kind of data with BI analyses. The complex indel coding method (Simmons and Ochterena, 2000) could probably generate even more useful phylogenetic signal out of the data. The only downside is that the step matrices produced by this method cannot be analyzed in a Bayesian framework.

Long-branch attraction-The substitution rate increase of Thismieae and the resulting long branches (Fig. 5) makes this group extremely vulnerable to long-branch attraction artifacts in the MP analyses. To rule out the possibility that the affinity of this group with Tacca is the result of such an artifact, we followed Bergsten (2005) and repeated the MP analyses with certain taxa excluded (see Materials and Methods). Because these tests were all negative and because the same ThismieaeTacca clade is retrieved by all BI analyses, we can confidently reject long-branch attraction as an explanation for this clade.

Phylogenetic implications-All analyses clearly support a strong relationship between Thismieae and Tacca, making both Burmanniaceae and Dioscoreaceae polyphyletic groups. This result contradicts a monophyletic Burmanniaceae as obtained in almost all previous molecular analyses (Caddick et al., 2000a, b; Neyland, 2002; Davis et al., 2004). In these studies, however, Burmanniaceae were always represented by a very limited number of taxa and low branch support was obtained for their monophyletic status. The topology also disagrees with a monophyletic Dioscoreaceae with $100 \%$ bootstrap support in Caddick et al. (2002a). The 18S rDNA analysis in that paper did recover a Tacca-Thismia clade, however. The monophyletic status of Dioscoreaceae in Caddick et al. (2002a) is consequently based on the included plastid DNA data, which does not support the affinity between Thismia and Tacca. In the separate $r b c L$ and $a t p B$ analyses, all Thismia samples, together with the achlorophyllous Burmannia species, fall together in an isolated position sister to all other included monocots. The highly diverged plastid DNA sequences from the achlorophyllous taxa are probably the cause of the strange plastid gene trees and the incongruence with the trees obtained with nuclear and mitochondrial data (Caddick et al., 2002a; this study).

In all topologies obtained in our analyses, the tribe Burmannieae is a strongly supported clade. The $18 \mathrm{~S}$ rDNA data place the clade sister to all other Dioscoreaceae and Thismieae, and nadl $b-c$ intron data suggest a sistergroup relationship with Dioscorea (including Stenomeris). This results in an unresolved position of the Burmannieae in the combined MP analysis, but the combined BI analysis favors a sister-group relationship with Dioscorea and Stenomeris. Although the basal relationships in the Burmannieae remain unclear, several well-supported clades are retained in all analyses.

The inclusion of Cymbocarpa in Gymnosiphon is not surprising because this genus differs from Gymnosiphon only by its peculiar dehiscence of the capsule (Jonker, 1938; Maas et al., 1986). The classification and species delineation of
Gymnosiphon has always been problematic due to their extreme vegetative reduction and the caducous upper part of the floral tube including the tepals and stamens. In our analyses a few well-supported clades are retrieved, but there seems to be neither morphological nor biogeographical evidence for these clades. The fact that the specimens of $G$. divaricatus and $G$. minutus do not form monophyletic groups further questions the species delimitation within the genus. Additional sampling and sequencing data of faster evolving DNA regions will be necessary to clarify the relationships in Gymnosiphon.

Sister to Gymnosiphon is the monotypic neotropical genus Hexapterella of which two specimens, one from French Guiana and one from Guyana, are included here. The sister-group relationship of Dictyostega with Hexapterella is very uncertain, and until sequencing data of the missing Burmannieae genera Campylosiphon, Miersiella, and Marthella are included, its position and consequently the relationships of all major Burmannieae clades inferred in this study will remain uncertain. This is also the case for Apteria, which seems to be related to the Dictyostega-Hexapterella-Gymnosiphon clade. The status of Apteria as a separate genus of Burmannieae has never been under debate, and our current data strongly support its monophyly.

An interesting paraphyly is found in the largest genus of Burmanniaceae, Burmannia, where the mycoheterotrophic species $B$. congesta and $B$. densiflora are part of the larger Burmannia clade. Both species are indigenous to West Africa, and together with the mycoheterotrophic Burmannia sphagnoides, they differ from the other Burmannia species by the absence of wings on their flower tubes and the presence of tuberous rhizomes. Some other species not sampled here show the same characteristics and sequencing data of those species is needed to evaluate the current paraphyletic status of Burmannia. The current phylogenetic hypothesis shows a puzzling biogeograpical pattern for Burmannia. In the $18 \mathrm{~S}$ rDNA majority rule tree, all neotropical Burmannia species are grouped in a monophyletic clade. The analysis of the mitochondrial data shows a different topology, with two independent origins of Burmannia in the neotropics. These two unrelated neotropical clades are retained in the consensus tree of the combined data. All Asian species are nested in between the neotropical and African species. The African B. latiata is not closely related with $B$. madagacariensis from Madagascar, and neither species grouped with the African $B$. congesta and $B$. densiflora. The basal position of $B$. congesta and $B$. densiflora might indicate an African origin of Burmannia, but the current topology lacks sufficient support for thorough biogeograpical considerations.

The Burmannieae relationships presented here do not conform to the proposed subdivision by Jonker (1938), who grouped Burmannia, Hexapterella, and Campylosiphon in the subtribe Euburmannieae and Apteria, Cymbocapra, Dictyostega, Marthella, and Miersiella in Apterieae. There is, however, certain agreement with the subdivision proposed by Miers (1847), who placed Apteria, Cymbocarpa, Dictyostega, and Gymnosiphon in a separate tribe from Burmannia based on their different number of carpels per ovary.

With our accessions of Afrothismia hydra and Haplothismia exannulata, data of Thismieae other than Thismia are included in a molecular phylogenetic analysis for the first time. The monophyly of the Thismieae is supported, and although the tribe's sister group relationship with Tacca is unexpected, there are some morphological similarities between the two groups 


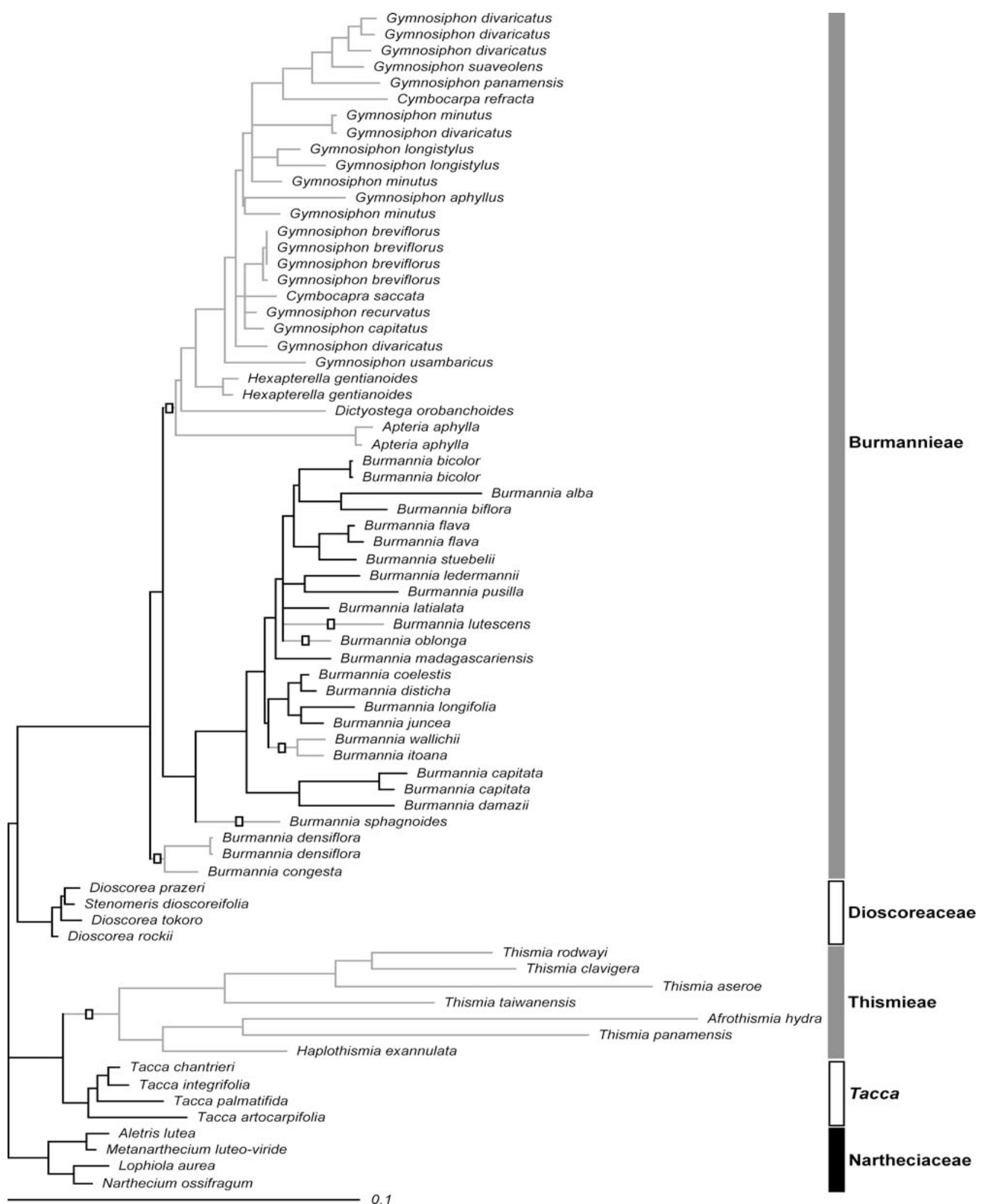

Fig. 6. Phylogram of the Bayesian analysis of the combined data. The scale bar represents 0.1 substitutions per site. Gray branches indicate achlorophyllous species, and boxes show loss of photosynthesis events. 
(Caddick et al., 2000a). Based on pollen morphological observations, a relationship between Taccaceae and Burmanniaceae has been rejected (Cranwell, 1953; Chakrapani and Ray, 1971). However, these observations included only few species of Thismia and Afrothismia. Although the interspecific relationships in Thismieae are beyond the scope of this paper, it is noteworthy to see that the only included neotropical Thismia, T. panamensis, does not group with the Asian Thismia species. Distinction of the Asian Thismia species from T. panamensis, Afrothismia, and Haplothismia is supported by their difference in subterranean structures. All sampled Asian Thismia species have fleshy, vermiform roots, while the neotropical Thismia species develop root tubers (Rübsamen, 1986). Afrothismia species have cylindrical rhizomes with several subglobose clusters of root tubercles, and Haplothismia is characterized by a clump of short, coralloid roots (Rübsamen, 1986; Imhof, 1999a; Sasidharan and Sujanapal, 2000; Maas-van de Kamer, 2003). Further sampling will be necessary to study the evolution and the phylogeny of Thismieae in general. In particular, sequencing data of Oxygyne and Tiputinia would be highly desirable, but both are extremely rare taxa that may defy rediscovery.

The loss of photosynthesis in Dioscoreales-Burmanniaceae, and especially the genus Burmannia, represent an interesting model to study the loss of photosynthesis in mycoheterotrophic plants because they include both green and achlorophyllous species. Since the Burmanniaceae are separated in Burmannieae and Thismieae in all our phylogenetic analyses, the loss of chlorophyll appears to have occurred independently in both groups (Fig. 6). In Burmannieae, a complex evolutionary pattern of achlorophylly is present. All genera, except Burmannia, are placed in a monophyletic achlorophyllous clade. Within Burmannia, there is a basal achlorophyllous clade ( $B$. congesta and $B$. densiflora), and the other achlorophyllous species are nested in between the autotrophic species, suggesting numerous independent events of loss of chlorophyll in the genus. This pattern is not unexpected. The importance of the presence/absence of chlorophyll as a useful character in the taxonomy of Burmannia has given up long ago (Jonker, 1938). Almost all Burmannia species show a degree of vegetative reduction, and in many chlorophyllous species the leaves are so reduced that the importance of mycorrhizal fungi as a source of carbon is undeniable. In some green-leaved species the stems and upper leaves are purple instead of green (e.g., B. stuebellii, B. biflora, $B$. vaupesana, B. damazii; Maas et al., 1986), indicating a fading or loss of chlorophyll dependence. The loss of chlorophyll in these plants just seems a "small" step in the process towards a full dependence on mycorrhizal fungi. The presence or absence of chlorophyll in Burmannia may therefore be regarded as a "quantitative" instead of a "qualitative" character. Furthermore, it is unclear whether reversals from heterotrophy to autotrophy are possible once a species has lost its photosynthetic function. The plastids of many mycoheterotrophs still contain (often highly divergent) amplifiable genes, but it remains unknown whether these genes have retained functionality (as $r b c L$ in some holoparasitic Scrophulariaceae; Wolfe and dePamphilis, 1998).

The independent origin of mycoheterotrophy in two clades of Dioscoreales is consistent with findings in other groups. Multiple origins of mycoheterotrophy are also found in Orchidaceae (Molvray et al., 1997, 2000) and in Gentianaceae
(Struwe and Albert, 2000; Struwe et al., 2002; Yuan et al., 2003), indicating that in certain lineages the genetic repertoire for a mycoheterotrophic lifestyle is present. The underlying processes for an adaptation to a mycoheterotrophic mode of life, however, still remain unknown.

\section{LITERATURE CITED}

Abe, C., AND Y. Akasawa. 1989. A new species of Oxygyne (Burmanniaceae) found in Shikoku, Japan. Journal of Japanese Botany 64: 161-164.

Airy-Shaw, H. K. 1952. A new genus and species of Burmanniaceae from South India. Kew Bulletin 2: 277-279.

APG. 1998. An ordinal classification for the families of flowering plants. Annals of the Missouri Botanical Garden 85: 531-553.

APG. 2003. An update of the angiosperm phylogeny group classification for the orders and families of flowering plants: APG II. Botanical Journal of the Linnean Society 141: 399-436.

Bergsten, J. 2005. A review of long-branch attraction. Cladistics 21: 163 193.

Bharathan, G., AND E. A. ZiMmer. 1995. Early branching events in monocotyledons-partial $18 \mathrm{~S}$ ribosomal DNA sequences. In P. J. Rudall, P. J. Cribb, D. F. Cutler, and C. J. Humphries [eds.], Monocotyledons: systematics and evolution, 81-107. Royal Botanic Gardens, Kew, UK.

BIDARTONDO, M. 2005. The evolutionary ecology of myco-heterotrophy. New Phytologist 167: 335-352.

Caddick, L. R., P. J. Rudall, and P. Wilkin. 2000a. Floral morphology and development in Dioscoreales. Feddes Repertorium 111: 189-230.

Caddick, L. R., P. J. Rudall, P. Wilkin, and M. W. Chase. 2000b. Yams and their allies: systematics of Dioscoreales. In K. L. Wilson and D. A. Morrison [eds.], Monocots: systematics and evolution, 475-487. Commonwealth Scientific and Industrial Research Organisation Publishing, Melbourne, Australia.

Caddick, L. R., P. J. Rudall, P. Wilkin, T. A. J. Hedderson, and M. W. ChAse. 2002a. Phylogenetics of Dioscoreales based on combined analyses of morphological and molecular data. Botanical Journal of the Linnean Society 138: 123-144.

Caddick, L. R., P. Wilkin, P. J. Rudall, T. A. Hedderson, and M. W. Chase. 2002b. Yams reclassified: a recircumscription of Dioscoreaceae and Dioscoreales. Taxon 51: 103-114.

Cameron, K. M., and M. W. Chase. 2000. Nuclear 18S rDNA sequences of Orchidaceae confirm the subfamilial status and circumscription of Vanilloideae. In K. L. Wilson and D. A. Morrison [eds.], Monocots: systematics and evolution, 457-471. Commonwealth Scientific and Industrial Research Organisation Publishing, Melbourne, Australia.

Chakrapani, P., and B. Raj. 1971. Pollen morphological studies in the Burmanniaceae. Grana 11: 164-179.

Chase, M. W. 2004. Monocot relationships: an overview. American Journal of Botany 91: 1645-1655.

Chase, M. W., D. E. Soltis, R. G. Olmstead, D. Morgan, D. H. Les, B. D. Mishler, M. R. Duvall, R. A. Price, H. G. Hills, Y.-L. Qiu, K. A. Kron, J. H. Rettig, E. Conti, J. D. Palmer, J. R. Manhart, K. J. Sytsma, H. J. Michaels, W. J. Kress, K. G. Karol, W. D. Clark, M. Hedrén, B. S. Gaut, R. K. Jansen, K.-J. Kim, C. F. Wimpee, J. F. Smith, G. R. Furnier, S. H. Strauss, Q.-Y. Xiang, G. M. Plunkett, P. S. Soltis, S. M. Swensen, S. E. Williams, P. A. Gadek, C. J. Quinn, L. E. Equiarte, E. Golenberg, G. H. Learn, S. W. Graham, S. C. H. Barrett, S. Dayanandan, and V. A. Albert. 1993. Phylogenetics of seed plants: an analysis of nucleotide sequences from the plastid gene rbcL. Annals of the Missouri Botanical Garden 80: 628-680.

Chase, M. W., D. E. Soltis, P. S. Soltis, P. J. Rudall, M. F. Fay, W. H. Hahn, S. Sullivan, J. Joseph, M. Molvray, P. J. Kores, T. J. Givnish, K. J. Sytsema, and J. C. PIREs. 2000. Higher-level systematics of the monocotyledons: an assessment of current knowledge and a new classification. In K. L. Wilson and D. A. Morrison [eds.], Monocots: systematics and evolution, 3-16. Commonwealth Scientific and Industrial Research Organisation Publishing, Melbourne, Australia.

Chase, M. W., D. W. Stevenson, P. Wilkin, and P. J. Rudall. 1995. 
Monocot systematics: a combined analysis. In P. J. Rudall, P. J. Cribb, D. F. Cutler, and C. J. Humphries [eds.], Monocotyledons: systematics and evolution, 475-487. CSIRO, Melbourne, Australia.

Cheek, M. 2003. A new species of Afrothismia (Burmanniaceae) from Kenya. Kew Bulletin 58: 951-955.

Cheek, M., and S. Williams. 1999. A review of African saprophytic flowering plants. In J. Timberlake and S. Kativu [eds.], African plants: biodiversity, taxonomy and uses, 39-49. Royal Botanic Gardens, Kew, UK.

Cheek, M., S. Williams, And M. Etuge. 2003. Kupea martinetugei, a new genus and species of Triuridaceae from western Cameroon. Kew Bulletin 58: 225-228.

Cranwell, L. M. 1953. New Zealand pollen studies. The monocotyledons. A comparative account. Bulletin of the Auckland Institute and Museum 3.

Davis, J. I., D. W. Stevenson, G. Petersen, O. Seberg, L. M. Cambell, V. F. Freudenstein, D. H. Goldman, C. R. Hardy, F. A. Michelangeli, M. P. Simmons, C. D. Specht, F. Vergara-Silva, and M. Gandolfo. 2004. A phylogeny of the monocots, as inferred from $r b c L$ and atpA sequence variation, and a comparison of methods for calculating jackknife and bootstrap values. Systematic Botany 29: 467-510.

Demesure, B., N. Sodzi, AND J. Petit. 1995. A set of universal primers for amplification of polymorphic non-coding regions of mitochondrial and chloroplast DNA in plants. Molecular Ecology 4: 129-131.

FranKe, T. 2004. Afrothismia saingei (Burmanniaceae, Thismieae), a new myco-heterotrophic plant from Cameroon. Systematics and Geography of Plants 74: 27-33.

Franke, T., L. Beenken, M. Döring, A. Kocyan, and R. Agerer. 2006. Arbuscular mycorrhizal fungi of the Glomus-group A lineage (Glomerales; Glomeromycota) detected in myco-heterotrophic plants from tropical Africa. Mycological Progress 5: 24-31.

Franke, T., M. N. Sainge, and R. Agerer. 2004. A new species of Afrothismia (Burmanniaceae; tribe: Thismieae) from the Western foothills of Mount Cameroon. Blumea 49: 451-456.

Freudenstein, J. V., AND M. W. Chase. 2001. Analysis of mitochondrial $n a d l b-c$ intron sequences in Orchidaceae: utility and coding of length-change characters. Systematic Botany 26: 643-657.

Hamby, K. R., AND E. A. Zimmer. 1988. Ribosomal RNA as a phylogenetic for inferring phylogeny within the grass family (Poaceae). Plant Systematics and Evolution 160: 29-37.

Huelsenbeck, J. P., and F. Ronquist. 2001. MRBAYES. Bayesian inference of phylogeny. Bioinformatics 17: 754-755.

IмHOF, S. 1999a. Anatomy and mycotrophy of the achlorophyllous Afrothismia winkleri. New Phylologist 144: 533-540.

Iмноғ, S. 1999b. Subterranean structures and mycorrhiza of the achlorophyllous Burmannia tenella (Burmanniaceae). Canadian Journal of Botany 77: 637-643.

IмноF, S. 2001. Subterranean structures and mycotrophy of the achlorophyllous Dictyostega orobanchoides (Burmanniaceae). International Journal of Tropical Biology and Conservation 49: 239-247.

JonkeR, F. P. 1938. A monograph of the Burmanniaceae. Mededeelingen Botanisch Museum Herbarium Rijksuniversiteit Utrecht 51: 1-279.

KIEw, R. 1999. Thismia goodii (Burmanniaceae), the blue capped Thismia, a new species from Borneo. Gardens' Bulletin Singapore 51: 179182.

LEAKE, J. R. 1994. The biology of myco-heterotrophic ('saprophytic') plants. New Phytologist 127: 171-216.

LEAKE, J. R. 2004. Myco-heterotroph/epiparasitic plant interactions with ectomycorrhizal and arbuscular mycorrhizal fungi. Current Opinion in Plant Biology 7: 422-428.

Liu, K. M., C. L. Long, AND Y. T. Liu. 2001. Burmannia hunanensis (Burmanniaceae), a new species from Hunan, China. Annales Botanici Fennici 38: 211-214.

Maas, P. J. M., H. MaAs-van de Kamer, J. van Benthem, H. C. M. SNELDERS, AND T. RÜBSAMEN. 1986. Burmanniaceae. Flora Neotropica 42: $1-189$.

MaAs-VAn de Kamer, H. 1998. Burmanniaceae. In K. Kubitzki [ed.], Families and genera of vascular plants, monocotyledons, Lilianae (except Orchidaceae), 154-164. Springer, Berlin, Germany.
MAAS-VAN DE KAMER, H. 2003. Afrothismia gesnerioides, another new species of Afrothismia (Burmanniaceae) from tropical Africa. Blumea 48: 475-478.

Maddison, D. R., And W. P. Maddison. 2001. MacClade 4: analysis of phylogeny and character evolution, version 4.01. Sinauer Associates, Sunderland, Massachusetts, USA.

Merckx, V., P. Schols, P. Maas, H. Maas-van de Kamer, and E. Smets. 2005. Phylogeny of Burmanniaceae: preliminary results based on $18 \mathrm{~S}$ rDNA sequences. In Proceedings of XVII International Botanical Congress, Vienna, Austria, 2005, 1399 (Abstract). Robidruck, Vienna, Austria.

MIERS, J. 1847. On a new genus of plants of the family Burmanniaceae. Proceedings of the Linnean Society London 1: 328-329.

Molvray, M., P. J. Kores, and M. W. Chase. 1997. Phylogeny and character evolution of Gastrodieae (Orchidaceae). American Journal of Botany 84 (Supplement): 217 (Abstract).

Molvray, M., P. J. Kores, and M. W. Chase. 2000. Polyphyly of mycoheterotrophic orchids and functional influences on floral and molecular characters. In K. L. Wilson and D. A. Morrison [eds.], Monocots: systematics and evolution, 441-448. Commonwealth Scientific and Industrial Research Organisation Publishing, Melbourne, Australia.

MülleR, K. 2005. SeqState: primer design and sequence statistics for phylogenetic DNA data sets. Applied Bioinformatics 4: 65-69.

Neyland, R. 2002. A phylogeny inferred from large-subunit (26S) ribosomal DNA sequences suggests that Burmanniales are polyphyletic. Australian Systematic Botany 15: 19-28.

Neyland, R., and M. Hennigan. 2003. A phylogenetic analysis of largesubunit (26S) ribosome DNA sequences suggests that the Corsiaceae are polyphyletic. New Zealand Journal of Botany 41: 1-11.

Nickrent, D. L., R. J. Duff, A. E. Colwell, A. D. Wolfe, N. D. Young, K. E. Steiner, and C. W. dePamphilis. 1998. Molecular phylogenetic and evolutionary studies of parasitic plants. In D. E. Soltis, P. S. Soltis, and J. J. Doyle [eds.], Molecular systematics of plants II, DNA sequencing, 211-241. Kluwer, New York, New York, USA.

Nickrent, D. L., And E. M. Starr. 1994. High rates of nucleotide substitutions in nuclear small-subunit (18S) rDNA from holoparasitic flowering plants. Journal of Molecular Evolution 39: 62-70.

Petersen, G., O. Seberg, J. I. Davis, and D. W. Stevenson. 2005. Mitochondrial sequences in monocot phylogenetics: new data, new problems. In Proceedings of XVII International Botanical Congress, Vienna, Austria, 2005, 197 (Abstract). Robidruck, Vienna, Austria.

Posada, D., and K. A. Crandall. 1998. MODELTEST: testing the model of DNA substitution. Bioinformatics 14: 817-818.

Ronquist, F., And J. P. Huelsenbeck. 2003. MrBayes 3: Bayesian phylogenetic inference under mixed models. Bioinformatics 19: 1572-1574.

Ronquist, F., J. P. HuelsenbeCK, ANd P. van der Mark. 2005. MrBayes 3.1 manual, Draft 5/17/2005. http://mrbayes.csit.fsu.edu/mb3. 1_manual.pdf [Accessed 18 May 2005].

Rübsamen, T. 1980. Beiträge zur Mikromorphologie der Testa und zur Embryologie amerikanischer Burmanniaceen und Triuridaceen 1: 1355; 2: 356-528. Msc. thesis, Ruhr-Universität, Bochum, Germany.

RüBSAMEN, T. 1986. Morphologische, embryologische und systematische Untersuchungen an Burmanniaceae und Corsiaceae (Mit Ausblick auf die Orchidaceae-Apostasioideae). Dissertationes Botanicae 92: 1310.

Sainge, M. N., AND T. Franke. 2005. A new species of Afrothismia (Burmanniaceae) from Cameroon. Nordic Journal of Botany 23: 299303.

Sasidharan, N., and P. Sujanapal. 2000. Rediscovery of Haplothismia exannulata Airy Shaw (Burmanniaceae) from its type locality. Rheedea 10: 131-134.

SCHLECHTER, R. 1906. Burmanniaceae africanae. Botanische Jahrbücher für Systematik, Pflanzengeschichte und Pflanzengeographie 38: 137143.

Simmons, M. P., and H. Ochoterena. 2000. Gaps as characters in sequence-based phylogenetic analyses. Systematic Biology 49: 369381. 
Soltis, D. E., AND P. S. Soltis. 1998. Choosing an approach and an appropriate gene for phylogenetic analyses. In D. E. Soltis, P. S. Soltis, and J. J. Doyle [eds.] Molecular systematics of plants II, DNA sequencing, 1-42. Kluwer, New York, New York, USA.

Soltis, D. E., P. S. Soltis, M. W. Chase, M. E. Mort, T. D. Albach, M. Zanis, V. Savolainen, W. H. Hahn, S. B. Hoot, M. F. Fay, M. Axtell, S. M. Swensen, L. M. Prince, W. J. Kress, K. C. Nixon, And J. S. FARRIS. 2000. Angiosperm phylogeny inferred from 18S rDNA, $r b c L$, and $a t p B$ sequences. Botanical Journal of the Linnean Society 133: 381-461.

Soltis, D. E., P. S. Soltis, D. L. Nickrent, L. A. Johnson, W. J. Hahn, S. B. Hoot, J. A. Sweere, R. K. Kuzoff, K. A. Kron, and M. W. Chase. 1997. Angiosperm phylogeny inferred from $18 \mathrm{~S}$ ribosomal DNA sequences. Annals of the Missouri Botanical Garden 84: 1-49.

Staden, R., K. Beal, and J. Bonfield. 1998. The Staden package. In S. Miseners and S. Krawetz [eds.], Computer Methods in Molecular Biology, 115-130. Humana Press, New York, New York, USA.

Stevenson, D. W., and H. Laconte. 1995. Cladistic analysis of monocot families. In P. J. Rudall, P. J. Cribb, D. F. Cutler, and C. J. Humphries [eds.], Monocotyledons: systematics and evolution, 685-735. Royal Botanic Gardens, Kew, UK.

Stone, B. 1980. Rediscovery of Thismia clavigera (Becc.) F.v.M. (Burmanniaceae). Blumea 26: 419-425.

Struwe, L., and V. A. Albert. 2000. Mycotrophic, non-chlorophyllous Voyria placed in Gentianaceae. American Journal of Botany 87 (Supplement): 161 (Abstract).

Struwe, L., J. W. Kadereit, J. Klackenberg, S. Nilsson, M. Thiv, K. B. von Hagen, and V. A. Albert. 2002. Systematics, character evolution, and biogeography of Gentianaceae, including a new tribal and subtribal classification. In L. Struwe and V. A. Albert [eds.], Gentianaceae: systematics and natural history, 21-309. Cambridge University Press, Cambridge, UK.

SwofFord, D. L. 2002. PAUP*: phylogenetic analysis using parsimony (*and other methods), version 4. Sinauer, Sunderland, Massachusetts, USA.

TAKhtajan, A. 1997. Diversity and classification of flowering plants. Columbia University Press, New York, New York, USA.

Thiele, K. R., And P. Jordan. 2002. Thismia clavarioides (Thismiaceae), a new species of fairy lantern from New South Wales. Telopea 9: 765771.

White, T. J., T. Burns, S. Lee, And J. TAYlor. 1990. Amplification and direct sequencing of fungal ribosomal RNA genes for phylogenetics. In M. Innis, D. Gelfand, J. Sininsky, and T. White [eds.], PCR protocols: a guide to methods and applications, 315-322. Academic Press, San Diego, California, USA.

Wilcox, T. P., F. J. Garcia de Leon, D. A. Hendrickson, and D. M. Hillis. 2004. Convergence among cave catfishes: long-branch attraction and a Bayesian relative rates test. Molecular Phylogenetics and Evolution 31: 1101-1113.

Wolfe, A. D., and C. W. DePamphilis. 1998. The effect of relaxed functional constraints on the photosynthetic gene $r b c L$ in photosynthetic and nonphotosynthetic parasitic plants. Molecular Biology and Evolution 15: 1243-1258.

Woodward, C., P. E. Berry, H. MaAs-van de Kamer, and K. Swing. In press. Tiputinia foetida, a new mycoheterotrophic genus of Thismiaceae from Amazonian Ecuador, and a likely case of deceit pollination. Taxon.

Wu, C-I., AND W.-H. LI. 1985. Evidence for higher rates of nucleotide substitution in rodents than in man. Proceedings of National Academy of Sciences, USA 82: 1741-1745.

YANG, S. Z., R. M. K. SAUNDERS, AND C. J. Hsu. 2002. Thismia taiwanensis sp. nov. (Burmanniaceae tribe Thismieae): first record of the tribe in China. Systematic Botany 27: 485-488.

Yuan, Y.-M., S. Wohlhauser, M. Möller, P. Chassot, G. Mansion, J. Grant, P. KüPfer, and J. Klackenberg. 2003. Monophyly and relationships of the tribe Exaceae (Gentianaceae) inferred from nuclear ribosomal and chloroplast DNA sequences. Molecular Phylogenetics and Evolution 28: 500-517.

ZhANG, D., AND R. M. SAunders. 1999. Burmannia larseniana (Burmanniaceae): a new species from Thailand. Nordic Journal of Botany 19: 241-244.

Zhang, D., AND R. M. SAunders. 2000. Systematics of the Burmannia coelestis complex (Burmanniaceae). Nordic Journal of Botany 20: $385-394$.

Zhang, D., R. M. SAunders, And C.-M. Hu. 1999. Corsiopsis chinensis gen. et sp. nov. (Corsiaceae): first record of the family in Asia. Systematic Botany 24: 311-314.

APPENDIX. Voucher information and GenBank accession numbers for taxa used in this study. Voucher specimens are deposited in the following herbaria: $\mathrm{NCU}=$ University of North Carolina, $\mathrm{U}=$ Nationaal Herbarium Nederland, Utrecht University Branch, SIU = Southern Illinois University, WAG $=$ Nationaal Herbarium Nederland, Wageningen University Branch, BR = National Botanic Garden of Belgium, K = Royal Botanic Gardens, Kew, $\mathrm{MCN}=$ McNeese State University, GENT = Gent University, L = Nationaal Herbarium Nederland, Leiden University Branch, PPI $=$ National Pingtung University of Science and Technology, YA = National Herbarium of Cameroon, KFRI = Kerala Forest Research Institute, HO = Tasmanian Museum \& Art Gallery, LV = Katholieke Universiteit Leuven, ISU = Illinois State University, US = Smithsonian Institution.

Taxon-GenBank accessions: 18S rDNA, nadl b-c; Voucher; Locality.

BurmanniaCeae; Tribe Burmannieae: Apteria aphylla (Nutt.) Barnh. ex Small-DQ786035, DQ786093; Chase 156, NCU; USA. Apteria aphylla (Nutt.) Barnh. ex Small-DQ786034, DQ786094; Maas et al. 9662, U; Guyana. Burmannia alba Mart.-DQ786074, DQ768133; Nakajima et al. 323, U; Brazil. Burmannia bicolor Mart.DQ786073, DQ786134; Maas et al. 9649, U; French Guiana. Burmannia bicolor Mart.-DQ786072, DQ786132; Ruysschaert 0636, GENT; Surinam. Burmannia biflora L.-DQ786070, DQ786142; Chase 157, NCU; USA. Burmannia capitata (Walt. ex Gmel.) Mart.-DQ786066, DQ786128; Neyland 958, MCN; USA. Burmannia capitata (Walt. ex Gmel.) Mart.-DQ786065, DQ786129; Maas et al. 9606, U; French Guiana. Burmannia coelestis DonDQ786068, DQ786123; Cameron s.n., NCU; Malaysia. Burmannia congesta (Wright) Jonk.-DQ786061, DQ786120; Jongkind 5463, WAG; Liberia. Burmannia damazii Beauverd-DQ786071, DQ786127; da Silva et al. 2195, U; Brazil. Burmannia densiflora Schltr.-DQ786060, DQ786122; de Wilde and van der Maesen 10912, WAG; Gabon. Burmannia densiflora Schltr.-DQ786059, DQ786121; van Nek 620, U; Gabon. Burmannia disticha L.-
U59947, DQ786124; Wilkin 1017, K; Thailand. Burmannia flava Mart.-DQ786076, DQ786131; Jansen-Jacobs et al. 5379, U; Guyana. Burmannia flava Mart.-DQ786077, DQ786130; daSilva et al. 2087, U; Brazil. Burmannia itoana Mak.-DQ786078, DQ786145; Kun-Ping Lo 821, PPI; Taiwan. Burmannia juncea Sol. ex R.Br.-DQ786063, DQ786143; Harwood 1499, BR; Australia. Burmannia latialata Pobég.-DQ786062, DQ786125; Jongkind 5923, WAG; Gabon. Burmannia ledermannii Jonk.-DQ786079, DQ786135; van Royen 4478, L; New Guinea. Burmannia longifolia Becc.-AF309398, DQ786138; Cameron s.n., NCU; Malaysia. Burmannia lutescens Becc.-AF309401, DQ786144; Caddick 352, K; Malaysia. Burmannia madagascariensis Mart.-AF309399, DQ786126; Caddick 312, K; Madagascar. Burmannia oblonga Ridl.-DQ786064, DQ786140; Wilkin 866, K; Thailand. Burmannia pusilla (Wall. ex Miers) Thw.-DQ786075, DQ786136; Madhusoodanan s.n., U; India. Burmannia sphagnoides Becc.AF309400, DQ786137; Caddick 348, K; Malaysia. Burmannia stuebelii Hieron. and Schltr.-DQ786067, DQ786139; Weigend 98/420, K; Peru. Burmannia wallichii (Miers) Hook.f.-DQ786069, 
DQ786141; Zhang s.n., K; Hong Kong. Cymbocarpa refracta Miers-DQ786038, DQ786095; Kress s.n., US; Costa Rica. Cymbocapra saccata Sandw.-DQ786039, DQ786096; Maas and Westra 4242, U; Guyana. Dictyostega orobanchoides (Hook.) Miers-DQ786056, DQ786119; Maas et al. 9620, U; French Guiana. Gymnosiphon aphyllus B1.-AF309402, DQ786102; Caddick 353, K; Malaysia. Gymnosiphon breviflorus GleasonDQ786041; DQ786098; Ek 1577, U; French Guiana. Gymnosiphon breviflorus Gleason-DQ786036, DQ786101; Maas et al. 9660, U; Guyana. Gymnosiphon breviflorus Gleason-DQ786040, DQ786099; Maas et al. 9676, U; Guyana. Gymnosiphon breviflorus GleasonDQ786037, DQ786100; Maas et al. 9675, U; Guyana. Gymnosiphon capitatus (Benth.) Urb.-DQ786054, DQ786114; Maas et al. 9616, U; Guyana. Gymnosiphon divaricatus (Benth.) Benth. and Hook.DQ786042, DQ786105; Fuchs and Zanella 21810, U; Colombia. Gymnosiphon divaricatus (Benth.) Benth. and Hook.-DQ786046, DQ786112; Mori et al. 10383, U; Brazil. Gymnosiphon divaricatus (Benth.) Benth. and Hook.-DQ786043, DQ786111; Maas et al. 9608, U; French Guiana. Gymnosiphon divaricatus (Benth.) Benth. and Hook.-DQ786045, DQ786106; Maas et al. 9638, U; French Guiana. Gymnosiphon divaricatus (Benth.) Benth. and Hook.DQ786044, DQ786107; Maas et al. 9657, U; Guyana. Gymnosiphon longistylus (Benth.) Hutch. and Dalziel-DQ786051, DQ786103; Breteler et al. 9705, WAG; Gabon. Gymnosiphon longistylus (Benth.) Hutch. and Dalziel-DQ786052, DQ786104; Breteler et al. 10967, WAG; Gabon. Gymnosiphon minutus Snelders and MaasDQ786049, DQ786110; Maas et al. 9612, U; French Guiana. Gymnosiphon minutus Snelders and Maas-DQ786048, DQ786109; Maas et al. 9651, U; French Guiana. Gymnosiphon minutus Snelders and Maas-DQ786047, DQ786108; Maas et al. 9668, U; Guyana. Gymnosiphon panamensis Jonk.-DQ786055, DQ786115; Wendt et al. 2312, U; Mexico. Gymnosiphon recurvatus Snelders and MaasDQ786050, DQ786116; Maas and Westra 4153, U; Guyana. Gymnosiphon suaveolens (Karst.) Urb.-U59942, DQ786097;
Nickrent 3005, SIU; Costa Rica. Gymnosiphon usambaricus Engl.-DQ786053, DQ786113; Bytebier 1217, BR; Kenya. Hexapterella gentianoides Urb.-DQ786058, DQ786117; Maas et al. 9659, U; Guyana. Hexapterella gentianoides Urb.-DQ786057, DQ786118; Maas et al. 9614, U; French Guiana.

Burmanniaceae; Tribe Thismieae: Afrothismia hydra Sainge and Franke-DQ786083, —; Sainge 910, YA; Cameroon. Haplothismia exannulata Airy Shaw-DQ786082, DQ786146; Sasidharan and Sujanapal 30476, KFRI; India. Thismia aseroe Becc.-AF309404, DQ786149; Caddick 349, K; Malaysia. Thismia clavigera (Becc.) F. Muell._AF309405, DQ786150; Caddick 354, K; Malaysia. Thismia panamensis (Standley) Jonk.-DQ786081, DQ786151; Aizprua 2946, LV; Panama. Thismia rodwayi F. Muell.-AF309403, DQ786148; Wapstra s.n., HO; Australia. Thismia taiwanensis Yang, Saunders and Hsu-DQ786080, DQ786147; Yang et al. 28981, PPI; Taiwan.

Dioscoreaceae: Dioscorea prazeri Prain and Burkill-DQ786089, DQ786156; Wilkin 878, K; Thailand. Dioscorea rockii Prain and Burkill-DQ786090, DQ786157; Chase 21052, K; Sri Lanka. Dioscorea tokoro Makino ex Myabe-DQ786088, DQ786158; Merckx 01, LV (Cultivated). Stenomeris dioscoreifolia Planch.DQ786087, DQ786159; Risdale 550, ISU; Philippines. Tacca artocarpifolia Seem.-AF309397, DQ786155; Caddick 305, K; Madagascar. Tacca chantrieri André-DQ786086, DQ786152; Chase 175, NCU (Cultivated). Tacca integrifolia Ker-Gawl.DQ786085, DQ786153; Boyce 1074, K; Malaysia. Tacca palmatifida Baker-DQ786084, DQ786154; Chase 1377, K; Indonesia.

NARTHECIACEAE: Aletris lutea Small-DQ786092, DQ786160; Anderson 36, LV; USA. Lophiola aurea Ker-Gawl.-DQ786091, DQ786161; Newell 23/8, K; USA. Metanarthecium luteo-viride Maxim.AF309410, DQ786162; Inoue s.n., K; Japan. Narthecium ossifragum Huds.-AF309411, DQ786163; Jaquemart 46-9, LV; Belgium. 